\title{
A Prospective Study of Clinical Characteristics and Interventions Required in Critically Ill Obstetric Patients
}

\author{
Jyotsna Suri ${ }^{1}$, Rohit Kumar ${ }^{2}$, Ayush Gupta ${ }^{3}$, Pratima Mittal ${ }^{4}$, Jagdish C Suri ${ }^{5}$
}

\begin{abstract}
Introduction: Obstetric patients are a special group of patients whose management is challenged by concerns for fetal viability, altered maternal physiology, and diseases specific to pregnancy.

Materials and methods: A prospective analysis of all obstetric patients admitted to the critical care department was done to assess reasons for transfer to the critical care unit (CCU) and the interventions required for management of these patients.

Results: Between June 2013 and September 2017, obstetric admission comprised 95 women (5.9\%) of the total critical care admissions. There were 77 patients $(81.1 \%)$ who were discharged from the hospital and 18 patients $(18.9 \%)$ died. In most of the cases, the primary reasons for shifting the patient to the CCU were severe preeclampsia with pulmonary edema (22.1\%), eclampsia (8.4\%), acute respiratory distress syndrome (ARDS) (14.7\%), and hypovolemic shock in antepartum hemorrhage (APH) and postpartum hemorrhage (PPH) (10.5 and 13.7\%, respectively). It was seen that 73 patients (76.8\%) required ventilator support, 58 patients (57.4\%) required vasopressor support, and intensive hemodynamic monitoring and blood/blood products were transfused in 55 patients (54.5\%). The need for ventilator support was more in patients with a lower $\mathrm{PaO}_{2} / \mathrm{FiO}_{2}$ and a higher APACHE II score. Patients with a high severity of illness score and a lower $\mathrm{PaO}_{2} / \mathrm{FiO}_{2}$ had higher odds of requiring vasopressors. Low hemoglobin at the time of transfer to the CCU and a prolonged hospital stay were found to predict the need for blood transfusion.

Conclusion: Obstetric patients are susceptible to critical illnesses but timely management improves the outcome of these young women.

Keywords: Blood transfusion, Echocardiography, Obstetric critical care.

Indian Journal of Critical Care Medicine (2020): 10.5005/jp-journals-10071-23519
\end{abstract}

\section{INTRODUCTION}

Obstetric patients are a special group of patients as their care must take into account both maternal and fetal well-being. During the pregnancy and puerperium, changes take place in maternal physiology to fulfill the needs of her health, fetus, and the newborn. These changes can unmask or at times worsen the underlying comorbidities. Furthermore, there may be complications of pregnancy or delivery itself requiring admission to the critical care unit (CCU). Obstetric patients have unique needs and often require management by a multidisciplinary team. There are a variety of reasons for shifting obstetric patients to the CCU and multiple supportive interventions may be required.

The concept of obstetric critical care provided by a multidisciplinary team including an obstetrician, critical care physician, neonatologist, and anesthesiologist within the precincts of the obstetric facility has developed over the last few years, which is at present radically different between different countries. ${ }^{1}$ Despite improved healthcare access to pregnant women, an alarmingly high maternal mortality rate still remains a challenge in developing countries. A dedicated obstetric critical care is lacking in most of the obstetric centers of India. ${ }^{2}$

We performed a prospective analysis of all critically ill obstetric patients admitted to the critical care department and analyzed the common reasons for transferring obstetric patients to the $\mathrm{CCU}$ and the treatments they required. Such recognition of these unique needs of the critically ill obstetric patients will allow better allocation of resources.

\section{Materials and Methods}

Safdarjung Hospital is a high-volume obstetric center and is a referral center for cases from various peripheral hospitals. In the period from April 2013 to August 2017, all obstetric admissions to

\footnotetext{
1,4 Department of Obstetrics and Gynecology, Vardhaman Mahavir Medical College and Safdarjung Hospital, New Delhi, India

2,3,5 Department of Pulmonary, Critical Care and Sleep Medicine, Vardhaman Mahavir Medical College and Safdarjung Hospital, New Delhi, India
}

Corresponding Author: Jagdish C Suri, Department of Pulmonary, Critical Care and Sleep Medicine, Vardhaman Mahavir Medical College and Safdarjung Hospital, New Delhi, India, Phone: +91 9810097259, e-mail: docjcsuri@gmail.com

How to cite this article: Suri J, Kumar R, Gupta A, Mittal P, Suri JC. A Prospective Study of Clinical Characteristics and Interventions Required in Critically III Obstetric Patients. Indian J Crit Care Med 2020;24(8):677-682.

Source of support: Nil

Conflict of interest: None

an eight-bedded CCU under the Department of Pulmonary and Critical Care Medicine were assessed prospectively. These patients were admitted during pregnancy as well as in the first 6 weeks of the postpartum period.

The patients were managed by the critical care team, comprising critical care consultants, the referring obstetric unit, and the neonatology team. The CCU has multiparameter monitors, microprocessor-controlled ventilators, and a bedside ultrasound/echocardiography machine. The critical care physicians are trained in point-of-care ultrasonography and perform lung ultrasound along with a deep vein thrombosis (DVT) screen and echocardiography; this was routinely performed for all patients. Cardiology and nephrology consultations were sought when necessary. The hospital also has a round-the-clock laboratory 
facilities and a well-equipped blood bank. Dialysis support is also available for patients in case of renal failure in addition to a 24 hour dedicated obstetric emergency OT.

\section{Data Collection}

The data collected included basic demographic data, parity, antepartum, or postpartum admission, obstetric and medical history. The reason for transfer to the hospital was classified as following: for hematological reasons (including coagulopathy due to hepatic reasons and severe anemia requiring immediate blood transfusion), after surgery, for hemodynamic support and monitoring; for neurological reasons, for renal failure or for respiratory failure. When there were multiple reasons for transfer, the treating physician was asked to classify based on the primary reason for transfer. The CCU course, blood transfusion received, treatment, and the need for vasopressor and ventilator support were also assessed.

\section{Statistical Analysis \\ Data Analysis}

All obstetric admissions were analyzed for their reason for transfer to the CCU, associated medical conditions, duration of stay, need for ventilator and vasopressor support, and the need for transfusion support. Parametric data were represented as mean and standard deviations, and categorical data were presented as percentage. Logistic regression was done to estimate the odds ratio for predicting the need for blood transfusion and the need for ventilator and vasopressor support. The Chi-square test was used to compare categorical variables. A " $p$ value" of less than 0.05 was considered significant.

\section{Results}

During the period from June 2013 to September 2017, the total admissions to the eight-bedded CCU were 1,598 of which the obstetric admissions accounted for 95 women (5.9\%). The details of the 95 patients are shown in Table 1. The mean age of the patients was $25.11 \pm 4.53$ years and the mean gestational age was $31.87 \pm$ 7.59 weeks. Only 36 patients (35.6\%) had received antenatal care during the pregnancy and $66.3 \%$ of the patients were anemic. Of these 95 patients, 77 (81.1\%) were discharged from the hospital and 18 (18.9\%) died.

In most cases, the primary reasons for shifting the patient to the ICU were for respiratory support in cases of severe preeclampsia with pulmonary edema (22.1\%), febrile illness with acute respiratory distress syndrome (ARDS) (14.7\%), and for hemodynamic support in hypovolemic shock [antepartum hemorrhage (APH) and postpartum hemorrhage (PPH)] (24.2\%) (Table 2). On assessing the services needed during the course of ICU stay (Table 3), it was seen that 73 patients $(76.8 \%)$ required ventilator support, 35 patients (36.8\%) required noninvasive ventilation, and 44 patients $(46.3 \%)$ required invasive mechanical ventilation. The need for ventilator support was more in patients with a lower $\mathrm{PaO}_{2} / \mathrm{FiO}_{2}(\mathrm{OR}=0.9927$; $95 \% \mathrm{Cl}=0.9878-0.9977 ; p$ value 0.002 ) and a higher APACHE II score (OR = 1.09; 95\% Cl = 1.00-1.19; $p$ value 0.034) (Table 4).

Fifty-eight patients $(57.4 \%)$ required vasopressor support and intensive hemodynamic monitoring. Patients with a high severity of illness score $(\mathrm{OR}=1.04 ; 95 \% \mathrm{Cl}=1.02-1.07$; $p$ value $<0.001$ for SAPS II, $\mathrm{OR}=1.33 ; 95 \% \mathrm{Cl}=1.14-1.56 ; p$ value $<0.001$ for $\mathrm{SOFA}$ and $\mathrm{OR}=1.14$; $95 \% \mathrm{Cl}=1.05-1.23 ; p$ value $<0.001$ for APACHE II score) and a lower $\mathrm{PaO}_{2} / \mathrm{FiO}_{2}(\mathrm{OR}=0.9957 ; 95 \% \mathrm{Cl}=0.9917-0.9997 ; p$ value 0.034$)$
Table 1: Clinical characteristics of obstetric patients in CCU

\begin{tabular}{|c|c|}
\hline Clinical characteristic & $n=95$ \\
\hline Age (years)* & $25.11 \pm 4.53$ \\
\hline \multicolumn{2}{|l|}{ Parity } \\
\hline Zero or 1 & $56(58.9 \%)$ \\
\hline $2 /$ more & $39(41.1 \%)$ \\
\hline Period of gestation (weeks)* & $31.87 \pm 7.59$ \\
\hline Antenatal care provided during pregnancy & $30(31.6 \%)$ \\
\hline \multicolumn{2}{|l|}{ Site from transfer to CCU } \\
\hline Transfer from emergency & $11(11.6 \%)$ \\
\hline Transfer from medicine ward & $5(5.1 \%)$ \\
\hline Transfer from obstetrics ward & $79(83.2 \%)$ \\
\hline \multicolumn{2}{|l|}{ Timing of transfer } \\
\hline Predelivery & $32(33.7 \%)$ \\
\hline Postdelivery & $54(56.8 \%)$ \\
\hline Postabortion & $9(9.5 \%)$ \\
\hline \multicolumn{2}{|l|}{ Previous medical diagnosis of: } \\
\hline Hypertension & $7(7.4 \%)$ \\
\hline Hypothyroidism & $2(2.1 \%)$ \\
\hline Diabetes mellitus & $2(2.1 \%)$ \\
\hline Anemia present & $63(66.3 \%)$ \\
\hline Hemoglobin* & $8.81 \pm 2.65$ \\
\hline $\mathrm{PaO}_{2} / \mathrm{FiO}_{2}{ }^{*}$ & $221.64 \pm 106.56$ \\
\hline SAPII* & $41.09 \pm 21.85$ \\
\hline SOFA* & $8.43 \pm 4.33$ \\
\hline APACHE II* & $18.29 \pm 8.12$ \\
\hline Duration of CCU stay (days)* & $4.71 \pm 3.24$ \\
\hline Duration of hospital stay (days)* & $6.92 \pm 4.03$ \\
\hline \multicolumn{2}{|l|}{ Maternal outcome } \\
\hline Alive & $77(81.1 \%)$ \\
\hline Death & $18(18.9 \%)$ \\
\hline Fetal outcome (alive) & $49(51.6 \%)$ \\
\hline
\end{tabular}

Data expressed as $n(\%)$

*Data expressed as mean \pm SD

$\mathrm{CCU}$, critical care unit; $\mathrm{PaO}_{2}$, partial pressure of oxygen in arterial blood; $\mathrm{FiO}_{2}$, fraction of inspired oxygen; SAPIl, simplified acute physiology score; SOFA, sequential organ failure assessment; APACHE II, acute physiology and chronic health evaluation; SD, standard deviation

Table 2: Primary indications for transfer to CCU

\begin{tabular}{lc}
\hline Reason for shifting patient & $n(\%)$ \\
\hline Severe anemia in failure & $6(6.3)$ \\
Coagulopathy with hepatic failure & $4(4.2)$ \\
Postsurgery intensive monitoring & $10(10.5)$ \\
APH & $10(10.5)$ \\
PPH & $13(13.7)$ \\
Eclampsia with recurrent seizures & $8(8.4)$ \\
Puerperal sepsis with renal failure & $4(4.2)$ \\
Severe preeclampsia with pulmonary & $21(22.1)$ \\
edema & \\
Peripartum cardiomyopathy & $5(5.2)$ \\
Febrile illness with ARDS & $14(14.7)$ \\
\hline
\end{tabular}

Data expressed as $n$ (\%)

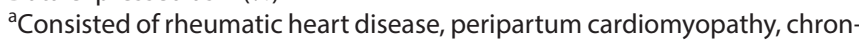
ic lung disorders 
Table 3: Interventions used for the management of the obstetric patients

\begin{tabular}{ll}
\hline Interventions in CCU & $n(\%)$ \\
\hline Number of patients requiring ventilator support \# & $73(76.8 \%)$ \\
Patients requiring NIV & $35(36.8 \%)$ \\
Average duration of NIV (in days)* & $3.97 \pm 2.33$ \\
Patients requiring invasive ventilation & $44(46.3 \%)$ \\
Average duration of invasive ventilation (in days)* & $3.50 \pm 3.08$ \\
Number of patients requiring vasopressor & $58(57.4 \%)$ \\
support & \\
Patients receiving blood transfusion & $55(57.9 \%)$ \\
$\quad$ Patients requiring PRBC transfusion & $52(54.7 \%)$ \\
$\quad$ Patients requiring PRP transfusion & $15(15.8 \%)$ \\
Patients requiring FFP transfusion & $8(8.4 \%)$ \\
Patients requiring renal replacement therapy & $6(6.31 \%)$
\end{tabular}

\#Six patients required both invasive and noninvasive ventilation

Data expressed as $n$ (\%)

* Data expressed as mean \pm SD

CCU, critical care unit; NIV, noninvasive ventilation; PRBC, packed red blood cells; PRP, platelet-rich plasma; FFP, fresh frozen plasma; SD, standard deviation had higher odds of requiring vasopressors. In addition, patients on invasive mechanical ventilation also often required vasopressor support $(\mathrm{OR}=6.66 ; 95 \% \mathrm{Cl}=2.68-16.52 ; p$ value $<0.001)$ (Table 5).

Blood/blood product was transfused in 55 patients (54.5\%). Low hemoglobin at the time of transfer to the ICU $(\mathrm{OR}=0.64 ; 95 \%$ $\mathrm{Cl}=0.51-0.79 ; p$ value $<0.001)$ and a prolonged hospital stay $(\mathrm{OR}=$ $1.18 ; 95 \% \mathrm{Cl}=1.02-1.36 ; p$ value 0.022 ) were found to predict the need for blood transfusion (Table 6). Six patients required renal replacement therapy and four patients required tracheostomy.

\section{Discussion}

The obstetric patients are often a young and previously healthy population with little prior comorbidity. Most of the patients in the current study were shifted to the CCU postpartum, which is in agreement with earlier observations. ${ }^{3-7}$ This reiterates the fact that the postpartum period is the most vulnerable time for critical complications such as decompensation of a previous known or unknown heart or pulmonary disease, which was a common reason for shifting the patient to the ICU. ${ }^{4}$

When primary indications for transferring obstetric patients to the ICU were assessed, a previous study had reported

Table 4: Factors predicting need for ventilator support

\begin{tabular}{|c|c|c|c|c|}
\hline Factors & $\begin{array}{l}\text { Ventilator support- } \\
\text { NO }(n=22)\end{array}$ & $\begin{array}{l}\text { Ventilator support- } \\
\text { YES }(n=73)\end{array}$ & pvalue & $\begin{array}{l}\text { Logistic regression [odds } \\
\text { ratio }(95 \% \mathrm{Cl}) \text { ] }\end{array}$ \\
\hline Age (years) & $26.00 \pm 5.03$ & $24.84 \pm 4.37$ & 0.293 & $0.94(0.85-1.04)$ \\
\hline \multicolumn{5}{|l|}{ Parity } \\
\hline Zero or 1 & $12(54.5 \%)$ & $44(60.3 \%)$ & 0.631 & 1.0 \\
\hline $2 /$ more & $10(45.5 \%)$ & $29(39.7 \%)$ & & $0.78(0.29-2.01)$ \\
\hline Period of gestation (weeks) & $32.59 \pm 6.20$ & $31.66 \pm 7.98$ & 0.616 & $0.99(0.92-1.06)$ \\
\hline Antenatal care provided during pregnancy & $8(36.4 \%)$ & $22(30.1 \%)$ & 0,607 & $0.96(0.36-2.57)$ \\
\hline Site from transfer to ICU & & & 0.933 & \\
\hline Transfer from emergency & $3(13.6 \%)$ & $8(10.9 \%)$ & & 1.0 \\
\hline Transfer from medicine ward & $1(4.5 \%)$ & $4(5.5 \%)$ & & $1.50(0.12-19.44)$ \\
\hline Transfer from obstetrics ward & $18(81.8 \%)$ & $61(83.6 \%)$ & & $1.39(0.34-5.81)$ \\
\hline Timing of transfer & & & 0.638 & \\
\hline Predelivery & $6(27.3 \%)$ & $26(35.6 \%)$ & & 1.0 \\
\hline Postdelivery & $13(59.1 \%)$ & $41(56.2 \%)$ & & $0.78(0.26-2.31)$ \\
\hline Postabortion & $3(13.6 \%)$ & $6(8.2 \%)$ & & $0.44(0.09-2.30)$ \\
\hline \multicolumn{5}{|l|}{ Previous medical diagnosis of } \\
\hline Hypertension & $1(4.5 \%)$ & $6(8.2 \%)$ & 0.486 & $2.04(0.24-17.54)$ \\
\hline Hypothyroidism & $0(0.0 \%)$ & $2(2.7 \%)$ & 0.999 & NE \\
\hline Diabetes mellitus & $0(0.0 \%)$ & $2(2.7 \%)$ & 0.999 & NE \\
\hline Anemia & $17(77.3 \%)$ & $46(63.0 \%)$ & 0.304 & $0.51(0.17-1.52)$ \\
\hline Hemoglobin & $8.15 \pm 3.18$ & $9.01 \pm 2.45$ & 0.181 & $1.14(0.95-1.37)$ \\
\hline $\mathrm{PaO}_{2} / \mathrm{FiO}_{2}$ & $282.81 \pm 87.38$ & $203.20 \pm 105.40$ & 0.002 & $0.9927(0.9878-0.9977)$ \\
\hline SAPSII & $33.73 \pm 15.40$ & $43.32 \pm 23.07$ & 0.071 & $1.02(0.99-1.05)$ \\
\hline SOFA & $7.77 \pm 3.56$ & $8.63 \pm 4.54$ & 0.418 & $1.04(0.92-1.17)$ \\
\hline APACHE II & $15.09 \pm 3.84$ & $19.26 \pm 8.82$ & 0.034 & $1.09(1.00-1.19)$ \\
\hline $\begin{array}{l}\text { Number of patients requiring vasopressor } \\
\text { support }\end{array}$ & $9(40.9 \%)$ & $48(65.8 \%)$ & 0.048 & $2.36(0.89-6.18)$ \\
\hline Number of patients requiring blood transfusion & $10(45.5 \%)$ & $42(57.5 \%)$ & 0.340 & $1.59(0.61-4.11)$ \\
\hline Duration of ICU stay (days) & $3.77 \pm 2.41$ & $4.99 \pm 3.42$ & 0.125 & $1.16(0.96-1.40)$ \\
\hline Duration of hospital stay (days) & $6.36 \pm 4.49$ & $7.08 \pm 3.90$ & 0.467 & $1.05(0.92-1.19)$ \\
\hline
\end{tabular}

Bold values $=$ statistically significant 


\begin{tabular}{|c|c|c|c|c|}
\hline Characteristics & $\begin{array}{l}\text { Did not receive vasopressor } \\
\text { support }(n=38)\end{array}$ & $\begin{array}{l}\text { Received vasopres- } \\
\text { sor support }(n=57)\end{array}$ & $p$ value & $\begin{array}{l}\text { Logistic regression } \\
\text { [odds ratio }(95 \% \text { CI)] }\end{array}$ \\
\hline Age (years) & $25.11 \pm 4.15$ & $25.11 \pm 4.81$ & 0.999 & $1.02(0.93-1.12)$ \\
\hline \multicolumn{5}{|l|}{ Parity } \\
\hline Zero or 1 & $23(60.5 \%)$ & $33(57.9 \%)$ & 0.834 & 1.0 \\
\hline $2 /$ more & $15(39.5 \%)$ & $24(42.1 \%)$ & & $1.28(0.57-2.87)$ \\
\hline Period of gestation (weeks) & $32.92 \pm 6.45$ & $31.18 \pm 8.25$ & 0.274 & $0.97(0.91-1.02)$ \\
\hline Antenatal care provided during pregnancy & $15(39.5 \%)$ & $15(26.3 \%)$ & 0.186 & $0.52(0.23-1.19)$ \\
\hline Site from transfer to ICU & & & 0.063 & \\
\hline Transfer from emergency & $1(2.6 \%)$ & $10(17.5 \%)$ & & 1.0 \\
\hline Transfer from medicine ward & $3(7.9 \%)$ & $2(3.5 \%)$ & & $0.07(0.00-1.02)$ \\
\hline Transfer from obstetrics ward & $34(89.5 \%)$ & $45(78.9 \%)$ & & $0.12(0.01-0.96)$ \\
\hline Timing of transfer & & & 0.287 & \\
\hline Predelivery & $11(28.9 \%)$ & $21(36.8 \%)$ & & 1.0 \\
\hline Postdelivery & $25(65.8 \%)$ & $29(50.9 \%)$ & & $0.59(0.25-1.42)$ \\
\hline Postabortion & $2(5.3 \%)$ & $7(12.3 \%)$ & & $2.0(0.36-11.21)$ \\
\hline \multicolumn{5}{|l|}{ Previous medical diagnosis of } \\
\hline Hypertension & $3(7.9 \%)$ & $4(7.0 \%)$ & 1.000 & $1.26(0.28-5.57)$ \\
\hline Hypothyroidism & $2(5.3 \%)$ & $0(0.0 \%)$ & 0.157 & NE \\
\hline Diabetes mellitus & $0(0.0 \%)$ & $2(3.5 \%)$ & 0.515 & NE \\
\hline Anemia & $25(65.8 \%)$ & $38(66.7 \%)$ & 1.000 & $1.09(0.48-2.53)$ \\
\hline Hemoglobin & $8.95 \pm 2.60$ & $8.73 \pm 2.69$ & 0.690 & $0.96(0.82-1.12)$ \\
\hline $\mathrm{PaO}_{2} / \mathrm{FiO}_{2}$ & $247.68 \pm 87.64$ & $204.28 \pm 114.98$ & 0.040 & $\begin{array}{l}0.9957(0.9917- \\
0.9997)\end{array}$ \\
\hline SAPSII & $32.08 \pm 11.81$ & $47.11 \pm 24.84$ & 0.001 & $1.04(1.02-1.07)$ \\
\hline SOFA & $6.32 \pm 2.84$ & $9.84 \pm 4.59$ & $<0.001$ & $1.33(1.14-1.56)$ \\
\hline APACHE II & $14.63 \pm 3.65$ & $20.74 \pm 9.31$ & $<0.001$ & $1.14(1.05-1.23)$ \\
\hline Number of patients requiring blood transfusion & $18(47.4 \%)$ & $34(59.6 \%)$ & 0.294 & $1.75(0.79-3.88)$ \\
\hline Number of patients requiring ventilator support* & $25(65.8 \%)$ & $48(84.2 \%)$ & 0.048 & $2.36(0.89-6.18)$ \\
\hline Patients requiring NIV & $18(51.2 \%)$ & $17(29.8 \%)$ & 0.089 & $0.43(0.19-0.97)$ \\
\hline Patients requiring IMV & $7(18.4 \%)$ & $37(64.9 \%)$ & $<0.001$ & $6.66(2.68-16.52)$ \\
\hline Duration of ICU stay (days) & $4.08 \pm 2.43$ & $5.12 \pm 3.65$ & 0.125 & $1.13(0.98-1.29)$ \\
\hline Duration of hospital stay (days) & $6.68 \pm 3.95$ & $7.07 \pm 4.11$ & 0.650 & $1.04(0.94-1.15)$ \\
\hline
\end{tabular}

Bold values $=$ statistically significant

hemodynamic instability as the most common cause followed by respiratory insufficiency and neurological dysfunction. ${ }^{8}$ Another study mentioned ventilator support alone as the most common cause followed by hemodynamic instability. ${ }^{9}$ In our experience, the common reason for transferring obstetric patients was for respiratory support in the majority of cases. This is partly explained as the CCU is under the team of pulmonary and critical care physicians and they are frequently called for the management of any respiratory failure in the hospital. We also observed that while only $24.2 \%$ were shifted to the CCU primarily for hemodynamic monitoring, after shifting, during the course of CCU stay, $60 \%$ patients required vasopressor support and intensive hemodynamic monitoring. In our experience, with the availability of bedside echocardiography and ultrasonography, we were able to detect cardiac dysfunction in the otherwise asymptomatic patients and could judiciously use vasopressors in the management of patients.

The need for services in the management of obstetric patients was also evaluated in the current study. Seventy-three patients $(76.8 \%)$ required ventilator support [with 44 patients (46.3\%) requiring invasive mechanical ventilation]. The ventilation rate among obstetric patients varies from 12 to $85 \%$ in studies depending on the cases admitted and the severity of illness. ${ }^{6,8-19}$ The median duration of ventilation in our study closely agrees with most Indian studies. ${ }^{8,11,20}$ Those patients who could be managed with noninvasive ventilation had a better outcome compared to patients who required invasive ventilation. It was also seen that patients with a high severity of illness and low $\mathrm{PaO}_{2} / \mathrm{FiO}_{2}$ were more likely to require ventilatory support.

In the present study, 57 patients $(60.0 \%)$ required inotropic support and 55 patients (57.9\%) required blood transfusion. We observed that the availability of bedside echocardiography was helpful in not only diagnosing but also effectively choosing the appropriate inotropic/vasopressor agent. The use of hemodynamic support and blood transfusion varies from 31 to $91 \%{ }^{8,11,21,22}$ and 46 to $70 \%,{ }^{10,16,22,23}$ respectively, in various studies. The high rate of ventilator and hemodynamic support and blood transfusion reflects the severity of illness of patients admitted as well as the tertiary referral center status of our hospital and prioritization of obstetric patients needing organ support for admission to our CCU. 


\begin{tabular}{|c|c|c|c|c|}
\hline Characteristics & $\begin{array}{l}\text { Did not receive blood } \\
\text { transfusion }(n=40)\end{array}$ & $\begin{array}{l}\text { Received blood transfu- } \\
\text { sion }(n=55)\end{array}$ & p value & $\begin{array}{l}\text { Logistic regression [odds } \\
\text { ratio }(95 \% \mathrm{Cl}) \text { ] }\end{array}$ \\
\hline Age (years) & $25.22 \pm 4.59$ & $25.02 \pm 4.52$ & 0.828 & $0.99(0.90-1.08)$ \\
\hline \multicolumn{5}{|l|}{ Parity } \\
\hline Zero or 1 & $26(65.0 \%)$ & $30(54.5 \%)$ & 0.399 & 1.0 \\
\hline $2 /$ more & $14(35.0 \%)$ & $25(45.5 \%)$ & & $1.55(0.67-3.58)$ \\
\hline Period of gestation (weeks) & $31.18 \pm 8.06$ & $32.38 \pm 7.26$ & 0.447 & $1.02(0.97-1.08)$ \\
\hline Antenatal care provided during pregnancy & $12(30.0 \%)$ & $18(32.7 \%)$ & 0.826 & $1.13(0.47-2.73)$ \\
\hline Site from transfer to ICU & & & 0.667 & \\
\hline Transfer from emergency & $4(10.0 \%)$ & $7(12.7 \%)$ & & 1.0 \\
\hline Transfer from medicine ward & $3(7.5 \%)$ & $2(3.6 \%)$ & & $0.38(0.04-3.34)$ \\
\hline Transfer from obstetrics ward & $33(82.5 \%)$ & $46(83.6 \%)$ & & $0.79(0.22-2.94)$ \\
\hline Timing of transfer & & & 0.691 & \\
\hline Predelivery & $13(32.5 \%)$ & $19(34.5 \%)$ & & 1.0 \\
\hline Postdelivery & $22(55.0 \%)$ & $32(58.2 \%)$ & & $0.99(0.41-2.42)$ \\
\hline Postabortion & $5(12.5 \%)$ & $4(7.27 \%)$ & & $0.55(0.12-2.43)$ \\
\hline \multicolumn{5}{|l|}{ Previous medical diagnosis of } \\
\hline Hypertension & $5(12.5 \%)$ & $2(3.6 \%)$ & 0.128 & $0.26(0.05-1.43)$ \\
\hline Hypothyroidism & $0(0.0 \%)$ & $2(3.6 . \%)$ & 0.507 & $\mathrm{NE}$ \\
\hline Diabetes mellitus & $1(2.5 \%)$ & $1(1.8 \%)$ & 1.000 & $0.72(0.04-11.90)$ \\
\hline Anemia & 19 (47.5\%) & $44(80.0 \%)$ & 0.002 & $4.42(1.78-10.94)$ \\
\hline Hemoglobin & $10.23 \pm 2.09$ & $7.78 \pm 2.53$ & $<0.001$ & $0.63(0.50-0.79)$ \\
\hline $\mathrm{PaO}_{2} / \mathrm{FiO}_{2}$ & $233.43 \pm 106.62$ & $213.06 \pm 106.67$ & 0.361 & $0.9982(0.9943-1.0021)$ \\
\hline SAPSII & $38.68 \pm 19.64$ & $42.85 \pm 23.34$ & 0.360 & $1.01(0.98-1.03)$ \\
\hline SOFA & $7.80 \pm 4.05$ & $8.89 \pm 4.49$ & 0.227 & $1.06(0.96-1.17)$ \\
\hline APACHE II & $15.35 \pm 5.76$ & $20.44 \pm 8.93$ & 0.002 & $1.10(1.03-1.18)$ \\
\hline $\begin{array}{l}\text { Number of patients requiring vasopressor } \\
\text { support }\end{array}$ & $20(50.0 \%)$ & $37(67.3 \%)$ & 0.096 & $2.05(0.89-4.75)$ \\
\hline $\begin{array}{l}\text { Number of patients requiring ventilator } \\
\text { support* }\end{array}$ & $28(70.0 \%)$ & $45(81.8 \%)$ & 0.221 & $1.93(0.74-5.05)$ \\
\hline Patients requiring NIV & $14(35.0 \%)$ & $21(38.2 \%)$ & 0.831 & $1.15(0.49-2.68)$ \\
\hline Patients requiring IMV & 15 (37.5\%) & $29(52.7 \%)$ & 0.152 & $1.86(0.81-4.26)$ \\
\hline Duration of ICU stay (days) & $4.08 \pm 2.54$ & $5.16 \pm 3.63$ & 0.107 & $1.12(0.97-1.30)$ \\
\hline Duration of hospital stay (days) & $6.45 \pm 3.63$ & $7.25 \pm 4.30$ & 0.339 & $1.05(0.94-1.17)$ \\
\hline
\end{tabular}

Bold values $=$ statistically significant

In the current study, we tried to assess the reasons for which obstetric patients are shifted to the CCU and the services that are required in their management. Obstetric patients frequently require ventilatory support (invasive and noninvasive), intensive hemodynamic monitoring (inotropic and vasopressor support), and blood transfusion; an adequately stocked blood bank is often instrumental in reducing maternal mortality. ${ }^{24}$ In addition, we felt that having the bedside ultrasound and echocardiography machine helped in effectively managing the patients.

The provision of these facilities in an obstetric CCU can help in effectively managing these patients and preventing mortality, which is the need of the hour. Our hospital has now established a dedicated obstetric CCU that is running successfully under the supervision of the obstetricians and with active involvement of the critical care team and the Department of Anesthesiology.

The limitation of our study is that being a single-center study, the sample size was modest. In addition, it was not always feasible to transfer all critically ill obstetric patients to the CCU and consequently, this study does not accurately represent all the critically ill obstetric patients treated in our center.

\section{Conclusion}

Obstetric patients are generally young and healthy. Despite this, maternal morbidity and mortality continues to occur and has implications for the family as well as the society. It is hoped that early detection and prompt referral to intensive care units could minimize the maternal mortality. The current study attempts to highlight the services that a dedicated obstetric critical care facility should have in order to effectively manage such patients.

\section{References}

1. Naylor Jr DF, Olson MM. Critical care obstetrics and gynecology. Crit Care Clin 2003;19(1):127-149. DOI: 10.1016/S0749-0704(02)00059-3.

2. Kaur M, Sharma J, Gupta P, Singh T, Mustafi S. Obstetric critical care requirements felt by the obstetricians: an experience-based study. J Anaesthesiol Clin Pharmacol 2017;33(3):381-386. DOI: 10.4103/joacp. JOACP_310_15.

3. Osinaike B, Amanor-Boadu S, Sanusi A. Obstetric intensive care: a developing country experience. Int J Anesthesiol 2006;10(2).

4. Keizer JL, Zwart JJ, Meerman RH, Harinck BI, Feuth HD, van Roosmalen J. Obstetric intensive care admissions: a 12 year review in a tertiary 
care centre. Eur J Obstet Gynecol Reprod Biol 2006;128(1-2):152-156. DOI: 10.1016/j.ejogrb.2005.12.013.

5. Kilpatrick SJ, Matthay MA. Obstetric patients requiring critical care. a five year review. Chest 1992;101(5):1407-1412. DOI: 10.1378/ chest.101.5.1407.

6. Lapinsky SE, Kruczynski K, Seaward GR, Farine D, Grossman RF. Critical care management of the obstetric patient. Can J Anaesth 1997;44(3):325-329. DOI: 10.1007/BF03015374.

7. Mahutte NG, Murphy-Kaulbeck L, Le Q, Solomon J, Benjamin A, Boyd ME. Obstetric admissions to the intensive care unit. Obstet Gynecol 1999;94(2):263-266. DOI: 10.1097/00006250-199908000-00021.

8. Gupta S, Naithani U, Doshi V, Bhargava V, Vijay BS. Obstetric critical care: a prospective analysis of clinical characteristics, predictability, and fetomaternal outcome in a new dedicated obstetric intensive care unit. Indian J Anaesth 2011;55(2):146-153. DOI: 10.4103/00195049.79895.

9. Chawla S, Nakra M, Mohan S, Nambiar BC, Agarwal R, Marwaha A. Why do obstetric patients go to the ICU? A 3 year-study. Med J Armed Forces India 2013;69(2):134-137. DOI: 10.1016/j.mjafi.2012.08.033.

10. Bhadade R, de' Souza R, More A, Harde M. Maternal outcomes in critically ill obstetrics patients: a unique challenge. Indian J Crit Care Med 2012;16(1):8-16. DOI: 10.4103/0972-5229.94416.

11. Ashraf N, Mishra SK, Kundra P, Veena P, Soundaraghavan S, Habeebullah S. Obstetric patients requiring intensive care: a one year retrospective study in a tertiary care institute in India. Anesthesiol Res Pract 2014;2014:789450. DOI: 10.1155/2014/789450.

12. Tang LC, Kwok AC, Wong AY, Lee YY, Sun KO, So AP. Critical care in obstetrical patients: an eight-year review. Chin Med J (Engl) 1997;110(12):936-941.

13. Crozier TM, Wallace EM. Obstetric admissions to an integrated general intensive care unit in a quaternary maternity facility. Aust $\mathrm{N} \mathrm{Z} \mathrm{J}$ Obstet Gynaecol 2011;51(3):233-238. DOI: 10.1111/j.1479-828X.2011. 01303.x.

14. Zwart JJ, Dupuis JR, Richters A, Ory F, van Roosmalen J. Obstetric intensive care unit admission: a 2 year nationwide population-based cohort study. Intensive Care Med 2010;36(2):256-263. DOI: 10.1007/ s00134-009-1707-x.
15. Leung NY, Lau AC, Chan KK, Yan WW. Clinical characteristics and outcomes of obstetric patients admitted to the intensive care unit: a 10 year retrospective review. Hong Kong Med J 2010;16(1):18-25.

16. Sriram S, Robertson MS. Critically ill obstetric patients in Australia: a retrospective audit of 8 years' experience in a tertiary intensive care unit. Crit Care Resusc 2008;10(2):124.

17. Togal T, Yucel N, Gedik E, Gulhas N, Toprak HI, Ersoy MO. Obstetric admissions to the intensive care unit in a tertiary referral hospital. J Crit Care 2010;25(4):628-633. DOI: 10.1016/j.jcrc.2010.02.015.

18. Jain M, Modi JN. An audit of obstetric admissions to intensive care unit in a medical college hospital of central India: lessons in preventing maternal morbidity and mortality. Int J Reprod Contracept Obstet Gynecol 2017;4(1):6.

19. Harde M, Dave S, Wagh S, Gujjar P, Bhadade R, Bapat A. Prospective evaluation of maternal morbidity and mortality in post-cesarean section patients admitted to postanesthesia intensive care unit. J Anaesthesiol Clin Pharmacol 2014;30(4):508-513. DOI: 10.4103/09709185.142844.

20. Gombar S, Ahuja V, Jafra A. A retrospective analysis of obstetric patient's outcome in intensive care unit of a tertiary care center. J Anaesthesiol Clin Pharmacol 2014;30(4):502-507. DOI: 10.4103/09709185.142843.

21. Jain S, Guleria K, Vaid NB, Suneja A, Ahuja S. Predictors and outcome of obstetric admissions to intensive care unit: a comparative study. Indian J Public Health 2016;60(2):159-163. DOI: 10.4103/0019557X.184575.

22. Ramachandra Bhat PB, Navada MH, Rao SV, Nagarathna G. Evaluation of obstetric admissions to intensive care unit of a tertiary referral center in coastal India. Indian J Crit Care Med 2013;17(1):34-37. DOI: 10.4103/0972-5229.112156.

23. Baskett TF, Sternadel J. Maternal intensive care and near-miss mortality in obstetrics. Br J Obstet Gynaecol 1998;105(9):981-984. DOI: 10.1111/j.1471-0528.1998.tb10261.x.

24. Bates I, Chapotera G, McKew S, Van Den Broek N. Maternal mortality in Sub-Saharan Africa: the contribution of ineffective blood transfusion services. BJOG 2008;115(11):1331-1339. DOI: 10.1111/j.14710528.2008.01866.x. 